\title{
Effects of experience on optomotor performance in the cichlid fish Aequidens latifrons
}

\author{
JACK IZOWER and LESTER R. ARONSON \\ American Museum of Natural History, New York, New York, 10024
}

\begin{abstract}
Laboratory-bred cichlid fishes, Aequidens latifrons, were tested individually in a modified optomotor apparatus in which the rotation of the vertically striped drum changed direction every $56 \mathrm{sec}$. Over a period of five consecutive daily tests, quantitative changes in optomotor behavior that are characterized as more efficient responding occurred. That is, the fish followed the moving stripes more accurately in all the measures that we used to define it. Retesting some subjects on Days 11-15, 43-47, and 89-93 showed that these changes in behavior persisted and are therefore characterized as a learning phenomenon. A hypothesis is presented concerning the ontogeny of optomotor behavior based on the experience gained by juveniles in viewing the conspicuous vertical stripes of other members of the school when following them.
\end{abstract}

Many fishes follow moving black and white vertical stripes by swimming in the direction of and at the speed of the movement. This behavior, the optomotor response, has been used to study behavior patterns such as schooling (Shaw, 1970; Shaw \& Tucker, 1965), orientation in a stream (Clausen, 1931; Lyons, 1904), swimming speed (Harden-Jones, 1963), visual sensitivity (Cronly-Dillon \& Sharma, 1968), and other behavior patterns involving visual-locomotor coordination (Springer, Easter, \& Agranoff, 1977). Little has been published concerning the development of optomotor behavior. It is often described as an innate act, a natural tendency to follow (Cronly-Dillon \& Muntz, 1965; Cronly-Dillon \& Sharma, 1968), and/or as an unconditioned reflex (Pavlov, 1966).

The purpose of the present work is to study the effects of experience in the performance of the optomotor response in fishes that are tested repeatedly. Since many investigators use optomotor performance as a quantitative measure of sightedness, they should be aware of the possibility that optomotor experience may play a role.

\section{METHOD}

The cichlid fishes, Aequidens latifrons (Steindachner), 6-9 cm long, were selected from a laboratory-bred stock. The experimental fish were individually housed in a constant light in 13-liter tanks visually separated from all other fish and were not disturbed except for feeding and testing.

The optomotor device consisted of two concentric plastic cylinders. The transparent inner stationary cylinder in which the subjects were tested was $14 \mathrm{~cm}$ high and $15 \mathrm{~cm}$ in diameter. The revolving outer cylinder was $25 \mathrm{~cm}$ high and $20 \mathrm{~cm}$ in diameter. The walls were covered with alternating black and white vertical bands, $1.5 \mathrm{~cm}$ wide, that subtended a series of $15-\mathrm{deg}$ angles.

This research was one part of a dissertation submitted by the first author to the faculty of the Graduate School of Arts and Sciences of New York University in partial fulfillment of the requirements of the degree of doctor of philosophy. We wish to express our appreciation to Madeline Cooper, Robert Stolberg, and Lawrence Picker for technical assistance and advice.
The drum was set to rotate at approximately $20 \mathrm{rpm}$, and the direction of rotation was changed at regular intervals.

The device was housed in a cabinet with an overhead $25-\mathrm{W}$ circular fluorescent light. The fish were viewed by means of a mirror tilted at $45 \mathrm{deg}$. The viewer could see the fish in the lighted cabinet, but with the room darkened, the fish could not see the viewer.

Close observation of the optomotor response showed it to be a complex behavioral pattern. We attempted to analyze this by quantifying the component parameters. Data were collected by typing a code on a 026 IBM keypunch machine that was adapted to advance $1 \mathrm{space} / \mathrm{sec}$. Different punched characters were used to represent the following behavior patterns, which were analyzed statistically by specially prepared computer programs.

(1) Initial latency is the time elapsed before a subject started to follow after a change in direction of drum rotation either by swimming backward or by turning and swimming forward. This parameter can be measured only if the subject followed the stripes in the preceding trial. (2) Turn latency is the interval between reversal of the direction of drum rotation and the time that the fish turned and swam forward in the new direction of the moving vertical stripes. (3) Swimming speed is determined by the number of times that a steadily swimming subject passed a marker between the 30 th and 45 th sec of the trial. It is a measure of gross locomotor activity and is a likely indicator of the physical condition of the subjects. (4) Forward turning frequency is the number of times that the subject reversed direction in order to follow the changed direction of the rotating drum. (5) Forward following duration is the total time that the subject followed the drum while swimming in the direction of rotation. (6) Stationary duration is the sum of the intervals in which the subject was stationary while the drum was revolving. (7) Opposite swimming duration is the total time that the fish swam counter to the direction of drum rotation.

Sixty-three experimentally naive, mature fish were placed individually in the inner cylinder of the optomotor device and were given $5 \mathrm{~min}$ to acclimate. When the device was turned on, the outer cylinder rotated for $56 \mathrm{sec}$ in one direction (Trial 1) and then reversed automatically and rotated for $56 \mathrm{sec}$ in the opposite direction (Trial 2). Reversals continued until each fish received 11 trials. The data from the first trial were discarded, thus providing data for five trials in each direction for each day. The subjects were given a preliminary run to acclimate them to the apparatus and were tested on the next 5 consecutive days. Seven of the above 63 fish were retested on Days 11-15 using the same testing procedure (Table 1). 
Table 1

Schedule of Optomotor Tests for Sham-Operated Subjects

\begin{tabular}{rrrrr}
\hline Group & \multicolumn{4}{c}{ Days } \\
\hline 63 Subjects & $1-5$ & & & \\
7 Subjects & $1-5$ & $11-15$ & & \\
8 Subjects & $1-5$ & & $43-47$ & $89-93$ \\
\hline
\end{tabular}

Table 2

Mean Performance of 63 Experimentally Naive Fish on Days 1 and 5

\begin{tabular}{lrrr}
\hline & \multicolumn{2}{c}{ Day } & \\
\cline { 2 - 3 } \multicolumn{1}{c}{ Behavior } & \multicolumn{1}{c}{1} & \multicolumn{1}{c}{5} & $\begin{array}{l}\text { Differ- } \\
\text { ence }\end{array}$ \\
\hline Initial Latency (in Seconds) & 10.7 & 6.8 & $-3.9^{*}$ \\
Turn Latency (in Seconds) & 15.7 & 11.8 & $-4.0^{*}$ \\
Swimming Speed (in Revolutions/15 sec) & 3.3 & 3.2 & $-.1 \dagger$ \\
Forward Turning (Frequency) & 9.8 & 10.0 & $+.2 \dagger \dagger$ \\
Forward Following (Duration in Seconds) & 37.8 & 43.6 & $+5.8^{*}$ \\
Stationary Stance (Duration in Seconds) & 6.1 & 2.5 & $-3.6^{*}$ \\
Opposite Swimming (Duration in Seconds) & 3.5 & 2.5 & $-1.0^{* *}$ \\
\hline
\end{tabular}

Note-Significance levels are based on student Newman-Keuls tests (Sokol \& Rohlf, 1969).

${ }^{*} p<.01 . \quad{ }^{* *} p<.05 . \quad \dagger p>.4 . \quad$ t $t p>.5$.

In addition to the main experiment, the initial latency data of eight additional subjects from another experiment were included. These fish were a control group for an experiment on cerebellar function. They were tested for 5 consecutive days and were then given a sham brain operation on Day 33 that involved opening the cranium and closing it again without touching the brain. On Days $43-47$ and again on Days 89-93, they were retested in the optomotor device (Table 1). These data had been recorded by typing a code on a typewriter in which the carriage automatically advanced $1 \mathrm{step} / \mathrm{sec}$. Otherwise, the procedure was the same as in the main experiment. Since these fish behaved in all respects like normal, intact fish, the data are included in this report.

\section{RESULTS}

The pooled data of 63 fish showed a significant change between Days 1 and 5 in all measures except swimming speed and frequency of forward turning to follow the drum (Table 2). The changed behavior was particularly evident in shorter initial response latencies and in following the direction of stripe rotation for longer periods. These scores clearly resembled learning acquisition curves (Figure 1).

Performance of the seven fish on Day 11, after a 5 -day rest was not significantly changed from the most efficient level previously achieved, that of Day 5 . This was also true of the eight additional subjects. After two rest periods of 38 days and 42 days, the latency levels were still lower than the Day 5 level (Table 3).

\section{DISCUSSION}

During the first 5 days of testing, naive fish progressively improved their optomotor responses by keeping up more accurately and consistently with the moving stripes. This was evidenced by increased durations of forward following, decreased initial and turn latencies, and decreased durations of opposite swimming and remaining stationary. These patterns stabilized at high performance levels and remained relatively unchanged for the duration of the tests (93 days for the sham operates). This long-term change of behavior, with a stable unchanged stimulus, conforms to commonly used definitions of learning (English \& English, 1958; Hinde, 1970).
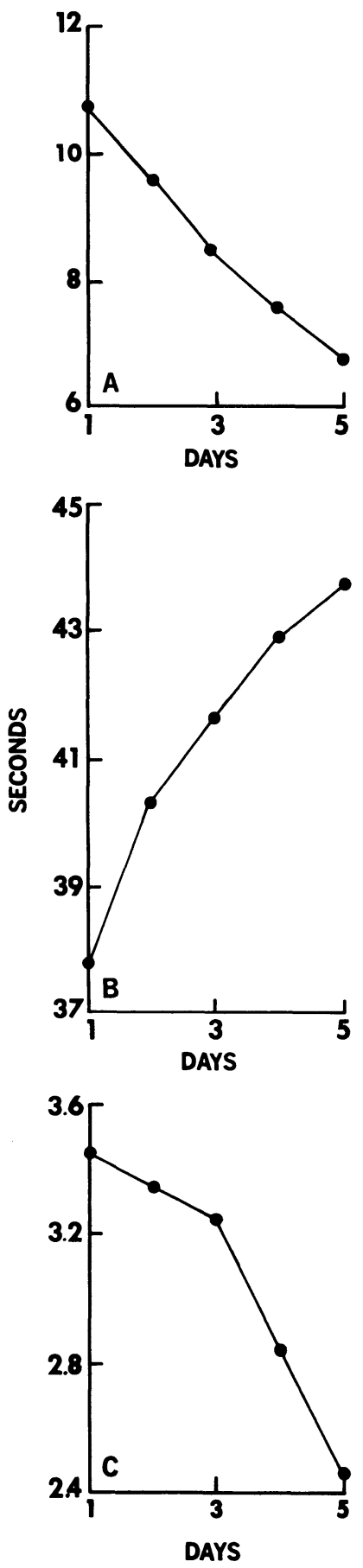

Figure 1. Changes from Days 1-5 in (A) initial latency, (B) duration of forward following, and (C) duration of opposite swimming. 
Table 3

Mean Initial Latency in Seconds

\begin{tabular}{rrrc}
\hline Day* & 63 Fish & 7 Fish & 8 Fish** \\
\hline 1 & 10.7 & 10.2 & 9.1 \\
5 & 6.8 & 6.8 & 8.2 \\
11 & & 6.5 & \\
15 & & 4.8 & \\
43 & & & 7.3 \\
47 & & & 6.5 \\
89 & & & 7.5 \\
93 & & & 6.2 \\
\hline
\end{tabular}

*First and last day of each test series.

* *Intact on Days 1-5; sham operated on Day 23.

One or more of the following factors may account for the improved performance: (1) The fish learned that the direction of drum rotation is constant for a fixed period of time (56 sec). (2) They learned to anticipate changes (drum starts to move or changes direction of rotation) and entered a heightened state of readiness to respond. (3) The moving stripes that continuously crossed the visual field were irritating to the fish, but the fish learned that the condition could be alleviated by swimming with the stripes. (4) They responded to cues that were not apparent to the investigator (e.g., possible changes in vibration of the motor). (5) They became accustomed to the strange testing situation (fear reduction). If increasing familiarity with the apparatus is a factor in improved optomotor responding, it is remotely possible that placing the subjects in the apparatus without revolving the drum might have the same effect. This question remains to be examined. On the other hand, the changes in optomotor behavior cannot be attributed to improved motor efficiency or improved physical stamina, since swimming speed and the frequency of turning remained almost unchanged throughout the testing period.

Of the 163 fish tested in our main experiment, 140 followed the drum in $90 \%$ or more of the trials during the 1st test day. Clearly, optomotor behavior is well organized in the adult population of our colony, and the present experiment, therefore, does not contribute directly to the question of experience in the ontogeny of this response. It should be noted, however, that our subjects were mature fish that had had prior experience as schooling juveniles, and Shaw (1970) has advanced the hypothesis that schooling mechanisms involve the optomotor response. Since juvenile Aequidens have conspicuous black and white vertical stripes on head, trunk, and tail, the young fish may act as cotomotor stimuli to each other. It may be that the strong initial optomotor responses that we observed in this species resulted from the long juvenile schooling experience characteristic of this species. It is also of interest that in the atherinid fish Menidia menidia, schooling behavior does not begin until 15-20 days after hatching, and the behavior is readily affected during this period by the social experiences of the individuals (Williams \& Shaw, 1971).

Takahashi, Murachi, and Karakawa (1968) observed that a training period was needed before inexperienced adult wild- caught Oryzias latipes would follow optomotor stripes with any degree of consistency and that training improved performance. Our much better initial performance on the first few days of testing might be due to differences in testing procedures, schooling experience of the juvenile fish, striped body patterns of the fish, or other species specific differences. In addition, Takahashi et al. used wild fish, whereas our fish were bred and maintained in the museum greenhouse.

Our findings show that most (but not all) parameters of the optomotor response are affected by optomotor experience. It is important, therefore, to take this finding into account in the design of future optomotor experiments by establishing stable baseline levels of responding before introducing experimental variables or by using control groups.

\section{REFERENCES}

Clausen, R. G. Orientation in freshwater fishes. Ecology, 1931, 12, 541-546.

Cronly-Dillon, J. R., \& Muntz, W. R. A. The special sensitivity of the goldfish and the clawed toad tadpole under photopic conditions. Journal of Experimental Biology, 1965, 42, 481-493.

Cronly-Dilloon, J. R., \& Sharma, S. C. Effect of season and sex on the photopic spectral sensitivity of the three-spined stickleback. Journal of Experimental Biology, 1968, 49, 679-687.

English, H. B., \& English, C. Psychological and psychoanalytical terms. New York: Longmans, Green, 1958.

Harden-Jones, F. R. The reaction of fish to moving backgrounds. Journal of Experimental Biology, 1963, 40, 437-446.

Hinde, R. A. Animal behaviour (2nd ed.). New York: McGrawHill, 1970.

Lyons, E. D. On rheotropism. I. Rheotropism in fishes. American Journal of Physiology, 1904, 12, 149-161.

Pavlov, D. S. Otnoshenie molodi rby k potoku vody i orientatsija v njom. Zoologisches Zhurnal, 1966, 45, 891-895.

Shaw, E. Schooling in fishes: Critique and review. In L. R. Aronson, E. Tobach, D. S. Lehrman, \& J. S. Rosenblatt (Eds.), Development and evolution of behavior: Essays in memory of T. C. Schneirla. San Francisco: Freeman, 1970.

Shaw, E., \& Tucker, A. The optomotor reaction of schooling carangid fishes. Animal Behaviour, 1965, 13, 330-336.

SокоL, R. R., \& RонцF, F. J. Biometry. San Francisco: Freeman, 1969.

Springer, A. D., Easter, S. S., Jr., \& Agranoff, B. W. The role of the optic tectum in various visually mediated behaviors of goldfish. Brain Research, 1977, 128, 393-404.

Takahashi, M., Murachi, S., \& Karakawa, Y. Studies on the optomotor reaction of fishes: Examination of the conditions necessary to induce the reaction of the Japanese killifish Orzyias latipes Temminck et Schlegel. Journal of the Faculty of Fish Animal Husbandry Hiroshima University, 1968, 7, 193-207.

Williams, M. M., \& Shaw, E. Modifiability of schooling behavior in fishes: The role of early experience. American Museum Novitates, 1971, 2448, 1-19.

(Received for publication April 1, 1980.) 